\title{
A LABORATORY STUDY ON ACID MODIFIED BITUMINOUS MIXES IN COMPARISON FOR RUTTING CHARACTERISTICS
}

\author{
${ }^{1}$ G ABDUL KHADER ${ }^{1}$, Dr.A.RAMESH ${ }^{2}$ and Dr. M. KUMAR ${ }^{3}$ \\ 1 -PG Student Dept. of Civil Engineering, VNR VignanaJyothi Institute of Engineering \\ and Technology, Hyderabad, Telangana, India. \\ 2-Associate Professor, Dept. of Civil Engineering, VNR VignanaJyothi Institute of \\ Engineering and Technology, Hyderabad, Telangana, India. \\ 3 -Professor, Dept. of Civil Engineering, University College of Engineering \\ OsmaniaUniversity, Hyderabad, Telangana, India.
}

\begin{abstract}
The rapid growth in trafficload intensity, tire pressure and traffic volume has put a hugedemand on pavements to perform satisfactorily for the design period. A number of efforts are made in the past to develop pavement materials that helped in attaining longer serviceability. Most of these efforts were directed towards improving the design of bituminous mix through modified bituminous binders. In this context an attempt is made to evaluate rutting characteristics of conventional bitumen modified with Poly phosphoric Acid (PPA). Immersion Type Wheel Rutting Machine was used for evaluation of rutting characteristics and is considered as one of the major critical criteria for design of pavement. Poly phosphoric Acid (PPA) is added as modifier to virgin bitumen (VG - 30) at regular interval of $1 \%$ up to $6 \%$ to the weight of Bitumen. Bituminous Concrete of Grade-II is considered for Analysis. Slabs of 400X300X50mm are prepared for evaluation of rutting characteristics. Stability, density, voids and flow parameters were determined using marshal test method for virgin and PPA modified mix. The result of immersion wheel rutting explains that acid modified binders resist more rutting compared to virgin binders. Acid modified mixes at 3\% optimum performs better in rutting characteristics when tested in laboratory for induced applied pressures, load and number of passes.
\end{abstract}

\section{KEYWORDS}

Poly phosphoric acid, bituminous concrete, rut depth

\section{INTRODUCTION}

Infrastructure facilities are provided for economic growth of countries progress. Pavement is a durable surface material laid down on ground surface intended to sustain vehicular traffic loading.Flexible pavements are vastly adopted in India as it provides ease in construction, operating and maintenance.Structural deterioration typically occurs due to fatigue cracking, rutting of the HMA pavement layers. Permanent deformation in the form of rutting is one of the most important distress (failure) mechanisms in bituminous pavements generally occurs with increase in truck tire pressure. In recent years, rutting has become the major distress in flexible pavement failure. Progression of rutting can lead to cracking and eventually leads to failure. Rutting accounts for a heavy portion of maintenance and costs high. Permanent deformation or DOI:10.5121/civej.2015.2403 
rutting in bituminous mixes depends on various factors such as aggregate gradation, shape and quality of aggregate, quantity andquality of binder, mix parameters such as amount of air voids and Voids in Mineral Aggregates (VMA), film thickness, temperature, and construction practices andEnvironmental conditions.In order to resist rutting on asphalt, the material shall be elastic which means it should have the ability to regain its original shape after removal of wheel load. Therefore complex shear modulus $\left(G^{*}\right)$ elastic portion, $G^{*} / \sin \delta$ should be large. Naturally higher the $\mathrm{G}^{*}$ value, stiffer is asphalt binder and will be able to resist deformation.Lower the phase angle $(\delta)$, the greater is the elastic portion of $G^{*}$ and will be able to recover its original shape after being deformed by a wheel load.The Dynamic Shear Rheometer (DSR) measures a specimen's complex shear modulus $\left(G^{*}\right)$ and phase angle $(\delta)$. The complex shear modulus $\left(G^{*}\right)$ can be considered the sample's total resistance to deformation when repeatedly sheared, while the phase angle $(\delta)$ is the lag between the applied shear stress and the resulting shear strain .The larger the phase angle $(\delta)$, the more viscous the material.This characterization is used in the SuperPave performance grade (PG). In India we still adopt viscosity grading (VG) as per MORTH guidelines.

Studies have revealed that properties of bitumen and bituminous mixes can improve/modify with the incorporation of certain additives or blend of additives. Properties of modified bitumen depend upon type and quantity of modifierused and process adopted for their manufacture. The advantages of modified bitumen includes

a) Lower susceptibility to temperature variations

b) Higher resistance to deformation at high pavement temperature

c) Delay of cracking and reflective cracking

d) Better age resistance properties

e) Better adhesion between aggregates and binder

f) Higher fatigue life of mixes

g) Overall improved performance

(Source: IRC: SP: 53-2010.)

A number of proprietary products are available in market with which bitumen can be modified. These modifiers shall comply with the above requirements besides conformity to specifications.

\subsection{Objectives of the present study}

Following are the objectives of the present investigation.

a) To ascertain optimum binder content for optimum Poly Phosphoric Acid (PPA)content when added at regular interval with virgin bitumen.

b) To study the rutting characteristics of virgin bituminous mix and PPA added modified bituminous mix.

\section{LITERATURE REVIEW}

Somewhere in the past studies it became an accepted practice to mix the Poly Phosphoric Acid with Bitumen available to them to improve the properties. Permanent deformation in flexible pavement is a major distress that is observed commonly in India and most of other developing countries. Many alternative procedures have been developed by various researchers by modifying conventional Bitumen with various admixes. Few of the contributions are summarized as follows; 
Ludomir (2006) explains the critical characteristics of asphalt mixes which control rutting potential and investigates the methods of laboratory testing which can be used to determine these characteristics. Geraint et al. (2007)explains an alternative to traditional analysis methods for flexible pavements using a three-dimensional finite element formulation based on a linear-elastic stress-strain law for the asphalt layer. Imran et al. (2010) explains permanent deformation of asphaltic concrete which depends on temperature, rate of loading and state of stress. Ahmad et al. (2011) evaluate rutting of dense graded hot mix asphalt (HMA) using the dynamic modulus Simple Performance test (SPT).Results from the study indicated that a correlation was found between the rut stiffness factors from SPT dynamic modulus test. Imad et al. (2011) explains the distribution of contact stress and to quantify its impact on viscoelastic pavement responses using a decoupled modeling approach. The authors developed a tire-pavement interaction model to predict the three-dimensional contact stresses under various loads and pressures. Nahi et al. (2011) developed a finite element model based on visco-plastic theory for simulating the laboratory testing of asphalt mixes in Hamburg Wheel Rut Tester (HWRT) for rutting and to model in-situ pavement performance. Alaaet al. (2012) develop a finite element model based on visco-plastic theory for simulating the laboratory testing of bituminous mixes in Hamburg Wheel Rut Tester (HWRT) for rutting and to model in-situ pavement performance. Kamran et al. (2012) evaluated the Mechanical Properties of three mixes, i.e., Marshall, SuperPave and Stone Mastic Asphalt (SMA) were evaluated by performing creep test, indirect tensile test and dynamic modulus in order to compare the performance of mixes. The study revealed that Super pave mixes performed better than Marshall and SMA. Olga et al. (2012) explains the application of poly phosphoric acid as binder modifier, used in production of warm asphalt mixes significantly mitigates the problem of moisture susceptibility and allows for production of moisture resistive final pavement.Ganesh et al. (2013)explains the investigation of rutting characteristics of bitumen mixes using plain bitumen (VG-10) and modified binders (CRMB-60 and PMB-70). PMB-70 binders perform better than VG-10 and CRMB-60 binders under the laboratory induced applied pressures and number of passes. Mohammed (2013) explains the effect of temperature on the rutting depth and plastic strain as a pavement response. The analysis of results showed that the rut depth and plastic strain increases with increasing the temperature. Chao et al. (2014) evaluated the rutting potential of two types of asphalt binders namely the neat binder and SBS modified binder by respectively using the oscillation-based parameter $\mathrm{G} * / \sin \delta$ and the oscillation-based nonrecoverable stiffness parameter $\mathrm{G}^{*} /(1-(1 / \tan \delta \sin \delta))$ as well as the MSCR-based non-recoverable compliance Jnr. Test results indicates that the parameter $G^{*} /(1-(1 / \tan \delta \sin \delta))$ exhibits a stronger correlation with the parameter Non-recoverable Compliance Jnr than that of parameter G*/sin $\delta$. Poornaet al. (2014)explains the percentage of Poly Phosphoric Acid (modifier) increases the Marshal Stability values and bulk density values are increased and decreases.Saad et al. (2014) in this work, the durability of reclaimed asphalt pavement after recycling were investigated in terms of rutting resistance and fatigue life. Three types of recycling agents (soft asphalt cement, soft asphalt cement blended with silica fumes and soft asphalt cement blended with fly ash) have been implemented in the construction of roller compacted asphalt pavement slab samples. Recycled sample with Soft Ac and Fly ash exhibits the highest tensile strain.Srinivasa et al. (2014)Binder rutting parameters such as $\mathrm{G}^{*} / \mathrm{sin} \delta$ and zero shear viscosity (ZSV) were measured using Dynamic Shear Rheometer (DSR) and rutting resistance of bituminous mixes was evaluated by an indigenously developed wheel tracking tester, IIT KGP Rut Tester.Vijay et al. (2014)explained the Rheological parameters such as complex modulus $\left(\mathrm{G}^{*}\right)$ and phase angle $(\delta)$ of these binders were evaluated using Dynamic Shear Rheometer for PMB-40, PMB-70 (SBSpolymer with 4\% content) and CRMB-60 (Crumb Rubber Modified Binder- rubber content of 6\%). An indigenously developed wheel tracker, IITKGP Rut tester was used to evaluate the rutting susceptibility of mixes. Correlations were developed between air voids. 
The present study is focused on the effect of rutting characteristics of bituminous concrete mixmodified with PPA. From the literature, it has been observed that many studies have been taken up by the researchers and have obtained good knowledge on the use different materials for improving the Bitumen properties. Different experiments have been conducted on modifying with poly phosphoric acid. Also, the changes in the properties, collapse, inundation stress and characteristics of modification in bitumen have been quantified.

However, limited or no literature has shown the comparison of the improvement of rutting properties, with poly phosphoric acid modified bituminous mixes.

\section{METHODOLOGY}

For the present investigation a following methodology has been opted to determine the rutting parameters of conventional and PPA modified mixes through optimum content of PPA and binder, from the past studies tests have been conducted as per codal provisions by AASTHO, ASTM, Indian standards, British standards and MORTH specifications which have been referred taking into laboratory conditions. Figure 1 is the flowchart of the methodology opted for the present study. As PPA is oligomer so commercially available liquid form of PPA is preferable for easy mixing with bitumen because as PPA is viscous in nature and the tests will be conducted for comparing the conventional mixes with PPA and varying acid content we can determine the optimum acid content also so that better acid content that can opted will be determined considering codes and specifications.

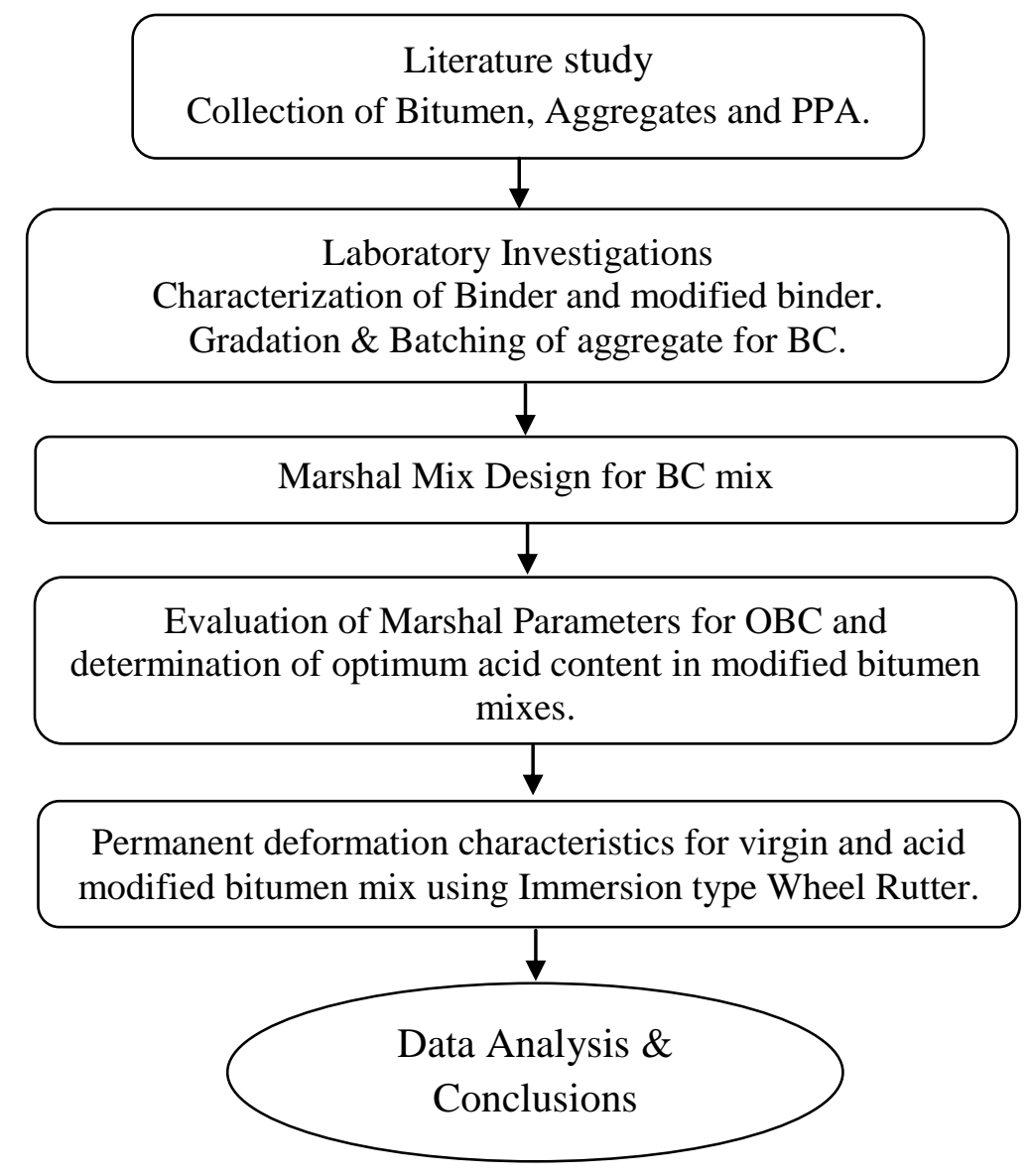

Figure 1. Methodology for Present Study 


\section{EXPERIMENTAL PROGRAMME}

In this study the stability analysis using marshal test and rutting characteristics using wheel rutting equipment for the conventional and modified PPA Bituminous Concrete mixes.

\subsection{MARSHAL TEST}

Optimum binder content, stability and air voids for Bituminous Concrete mixes for determined using marshal test and was performedin accordance of ASTM D5581 - 07A (2013). A Bituminous Concrete mix of Grade -II was considered as per MORTH specifications. Specimens were prepared by using Automatic Compactor with 75 blows on each side of specimen in accordance of ASTM D 6926-04 with a range of binder content (4.5-6.0\%).84 specimens for both Conventional and PPA modified mixes were prepared to conduct marshal test to obtain optimum PPA content at $4 \%$ Air Voids and for $65-75 \%$ of Voids Filled by Bitumen as per MORTH specifications. The Marshall stability of the mix is defined as the maximum load carried by the specimen at a standard test temperature of $60^{\circ} \mathrm{C}$. The flow value is the deformation that the test specimen undergoes during loading up to the maximum load. Flow is measured in $0.25 \mathrm{~mm}$ units. In this test, an attempt is made to obtain optimum binder content for the type of aggregate mix used and the expected traffic intensity. Figure 2 provides the samples used for evaluation of marshal parameters.
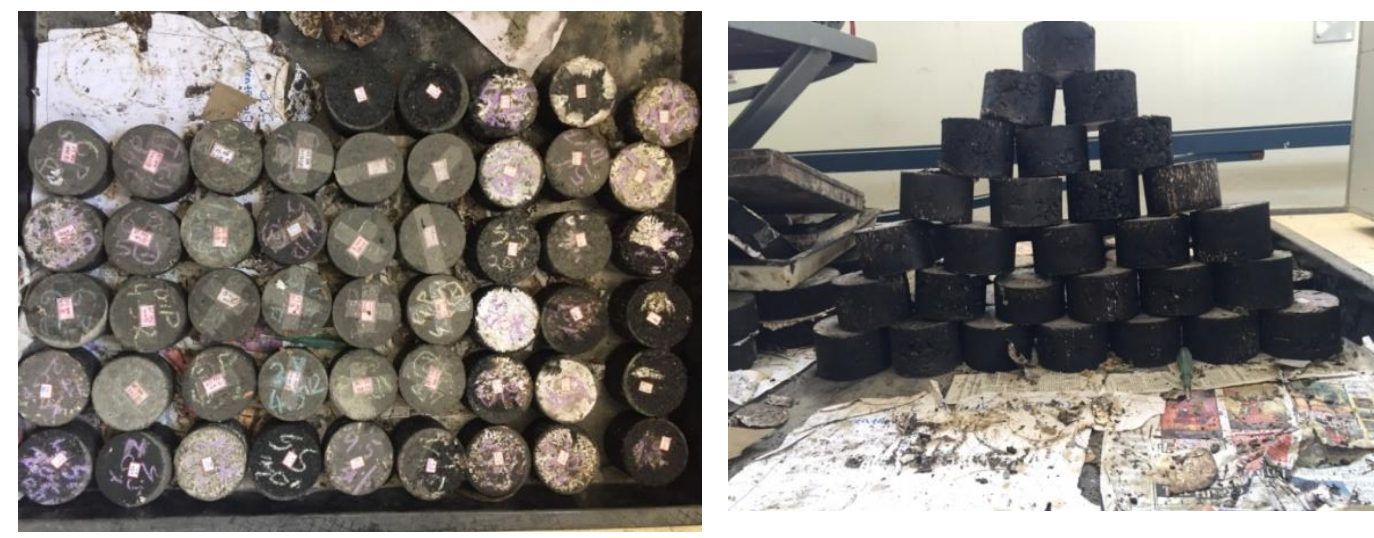

Figure2.Samples for Marshal Test

\subsection{WHEEL RUTTING TEST}

Rutting characteristics was carried on Immersion Type Wheel Tracking Device and was as per AASHTO-T324 test guidelines.Rectangular slabs of dimensions 400X300X50mm were prepared for conventional and PPA modified Bituminous Concrete mixes as per AASTHO T 283\&BS EN 1269733 (2007) using Roller Compactor.In order to obtain slabs of the desired density and size, an initial levelling cycle may be actuated that is intended for evenly distributing the mix in the mold. The compacting phase may be programmed with constant or increasing load, i.e. with increasing deformation. It is possible to set a defined slab thickness or the number of cycles. A kneading system is used for compaction and consists in positioning between the roller and bituminous mixture a series of sliding metal plates that are free to move vertically, guided by the internal mold surfaces. The wheel tracking test apparatus is the small size type prescribed in the Standard.A series of test specimens are prepared for each optimum percentage of binder content, 
for conventional and $1 \%$ to $6 \%$ PPA modified with uniform rate of $1 \%$ to weight of Bitumen are prepared. The test was conducted at $35^{\circ} \mathrm{C}$ in which the specimens were subjected to simulated trafficking with a simple harmonic motion with a wheel load of $710 \mathrm{~N}$ and a wheel pressure of $0.258 \mathrm{~N} / \mathrm{mm}^{2}$ along larger side of straight path. A LVDT is also provided to the side of wheel for monitoring rut depth to corresponding number of wheel passes. Though the instrument was Immersion type this study was comprises only for non-immersion test which test temperature and sample temperature was $35^{\circ} \mathrm{C}$ and was non-immersed.Figure 3 is the slab sample which was compacted using roller compactor for each optimum binder content to an acid content of $1 \%, 3 \%$ and 5\%. Figure 4 is the immersion type wheel rutting machine setup indicating the LVDT connection, sample provided for test and steel wheel to run on a bituminous concrete sample.

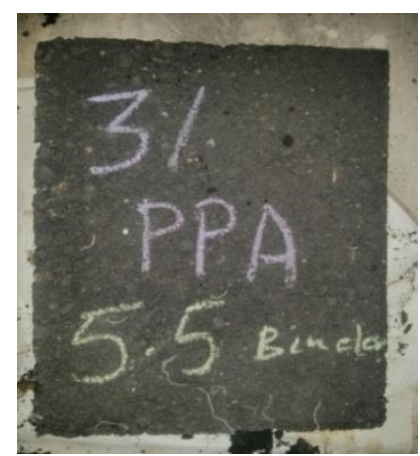

Figure 3. Rectangle slab

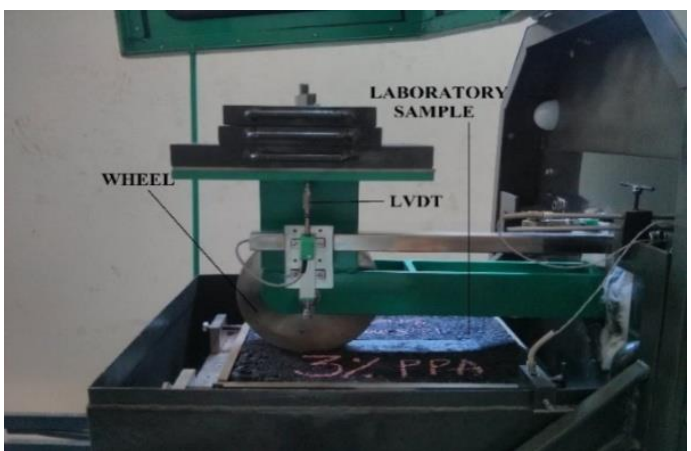

Figure 4. Immersion type wheel Rutter Setup

\section{EXPERIMENTAL RESULTS}

Aggregates for BC grade II specifications as per MORTH specification have been collected from local quarry. Basic material properties have been determined as per codeprovisions. Physical properties as abrasion, impact value, shape and crushing value are performed and are reported in Table 1. Consistency test on bitumen as penetration, ductility, softening point and viscosity were performed and results are presented in Table 2. PPA as a modified was added to virgin bitumen percentages. PPA was mixed in VG-30 virgin binder using high speed Mechanical Stirrer for homogeneous mixes. PPA was added to the weight of bitumen. Bituminous Concrete of Grade-II selected and is shown in figure 5 .

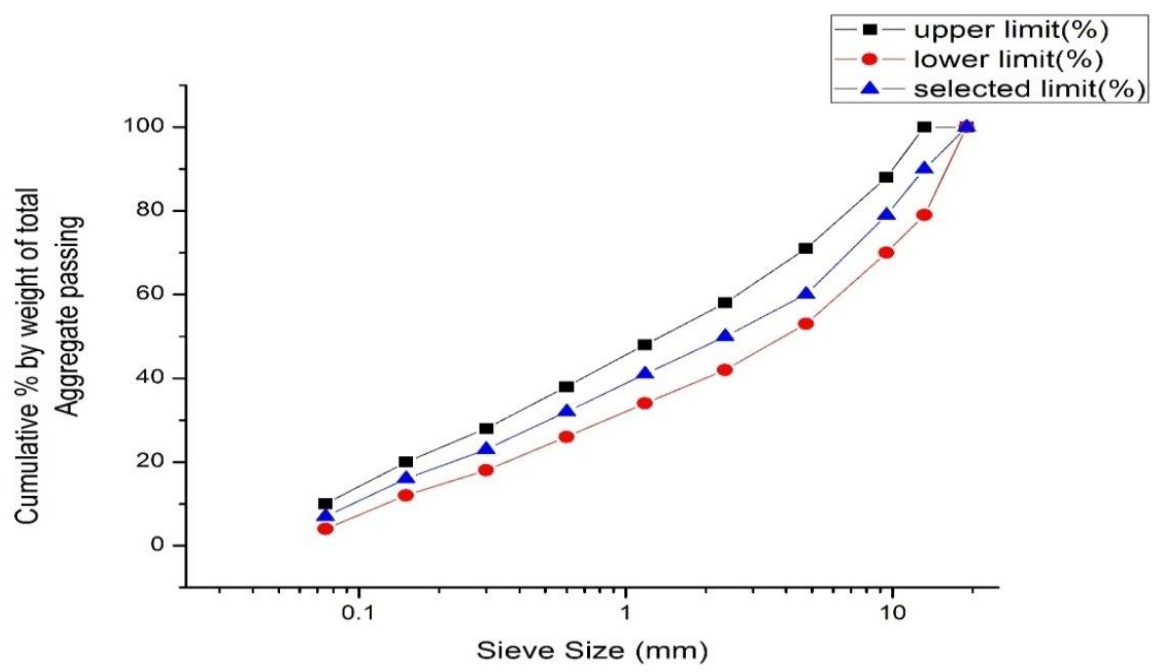

Figure 5. Gradation curve of aggregates that have adopted as per MORTH specifications 
Table 1. Physical Properties of Aggregates

\begin{tabular}{|c|c|c|c|c|}
\hline S. No. & Test Property & $\begin{array}{c}\text { MORTH } \\
\text { Obtained } \\
\text { Values }\end{array}$ & $\begin{array}{c}\text { Mocifications } \\
\text { (Clause 509.2) }\end{array}$ & Test standard \\
\hline 1 & Abrasion Value & $22 \%$ & Max. 40\% & IS: 2386(Part 4) \\
\hline 2 & Impact Value & $17 \%$ & Max. 30\% & IS: 2386(Part 4) \\
\hline 3 & $\begin{array}{c}\text { Combined Value } \\
\text { (Flakiness \& elongation ) }\end{array}$ & $22 \%$ & Max. 30\% & IS: 2386(Part 1) \\
\hline 4 & Specific gravity & 2.704 & $2.6-2.8$ & IS: 2386(Part 3) \\
\hline 5 & Crushing Value & 19 & Max. 40\% & IS: 2386(Part 4) \\
\hline
\end{tabular}

Table 2. Physical Properties of Bitumen

\begin{tabular}{|c|c|c|c|c|c|c|c|c|}
\hline Test & \multirow{2}{*}{ Test Method } & \multicolumn{7}{|c|}{ PPA Content } \\
\cline { 3 - 9 } Properties & $\mathbf{0 \%}$ & $\mathbf{1 \%}$ & $\mathbf{2 \%}$ & $\mathbf{3 \%}$ & $\mathbf{4 \%}$ & $\mathbf{5 \%}$ & $\mathbf{6 \%}$ \\
\hline $\begin{array}{c}\text { Penetration } \\
\left(1 / 10^{\text {th }} \text { of mm }\right)\end{array}$ & IS:1203 & 64 & 64 & 60 & 57 & 54 & 51 & 40 \\
\hline $\begin{array}{c}\text { Softening point } \\
\left({ }^{\circ} \mathrm{C}\right)\end{array}$ & IS:1205 & 56 & 57 & 59 & 61 & 64 & 64 & 70 \\
\hline Ductility (mm) & IS:1208 & 69 & 71 & 76 & 78 & 74 & 71 & 60 \\
\hline $\begin{array}{c}\text { Absolute } \\
\text { viscosity } \\
\left(60^{\circ} \mathrm{C}\right)(\text { poise })\end{array}$ & $\begin{array}{c}\text { IS:1206 (Part } \\
2)\end{array}$ & 2580 & 2560 & 2544 & 2510 & 2486 & 2360 & 2290 \\
\hline
\end{tabular}

\subsection{MARSHAL TEST RESULTS OF PPA MODIFIED BITUMINOUS CONCRETE MIXES}

The marshal stability test was conducted on prepared conventional mixes and modified PPA mixes as per ASTM D 1559 to determine properties such as Bulk Density, Voids Filled by Bitumen, Stability, Flow and Air Voids in mixes using MORTH specifications.The Marshall Stability and flow test provides the performance prediction measure for the Marshall Mix design method. The stability portion of the test measures the maximum load supported by the test specimen ay a loading rate of $50.8 \mathrm{~mm} /$ minute and at $60^{\circ} \mathrm{C}$ tests temperature. Basically, the load is increased until it reaches a maximum then when the load just begins to decrease, the loading is stopped and the maximum load is recorded. Marshal test was conducted at $60^{\circ} \mathrm{C}$ by applying load the specimen starts absorbing load up to its strength and starts failure showing cracks on the faces of diameter of the specimen, through the connected LVDT and signal conditioner for data acquisition software the load and deflection behavior was monitored. The load and flow parameters were obtained from the data acquirer, the remaining parameters were calculated as per MORTH specifications considering limits and was listed as table 3.Figure 6 shows the marshal test along with data acquisition and signal conditioner. Figure 7 provides how the failure of marshal samples were after the application of load. 
Civil Engineering and Urban Planning: An International Journal(CiVEJ) Vol.2,No.4, December 2015

The PPA modified specimens also prepared and were tested and the parameters were compared between conventional and PPA contents to determine how the strength and voids were changing with respect to binder and PPA addition to a mix. For the optimum binder content the further study was carried out.

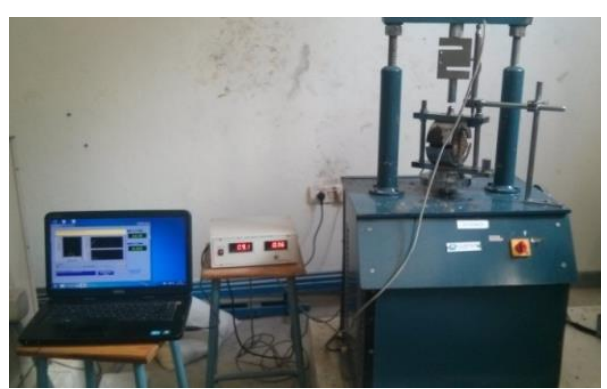

Figure 6. Marshall Test with Data Acquisition

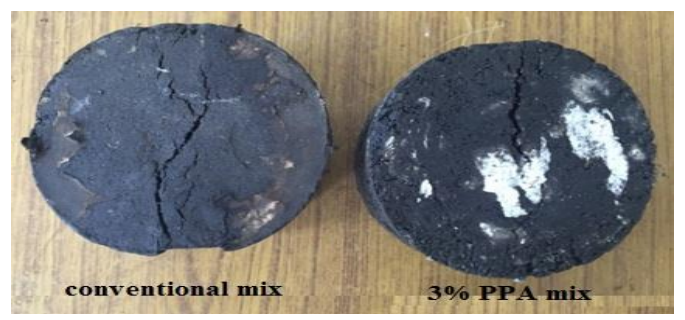

Figure 7.Position of Sample after the Test

Table 3. Marshal Test Properties of Conventional and PPA Modified Mixes

\begin{tabular}{|c|c|c|c|c|c|}
\hline $\begin{array}{l}\text { Binder } \\
(\%)\end{array}$ & $\begin{array}{l}\text { Bulk Specific } \\
\text { gravity }(\mathrm{gm} / \mathrm{cc} .)\end{array}$ & $\begin{array}{c}\text { Air Voids } \\
(\%)\end{array}$ & $\operatorname{VFB}(\%)$ & $\begin{array}{l}\text { Flow } \\
(\mathrm{mm})\end{array}$ & $\begin{array}{c}\text { Marshall } \\
(\mathrm{Kn})\end{array}$ \\
\hline \multicolumn{6}{|c|}{ PPA CONTENT - $0 \%$} \\
\hline 4.5 & 2.31 & 8.28 & 57.3 & 3.53 & 9.67 \\
\hline 5 & 2.36 & 5.34 & 68.62 & 3.97 & 10.81 \\
\hline 5.5 & 2.37 & 4.06 & 72.51 & 4.09 & 12.03 \\
\hline 6 & 2.35 & 2.84 & 88.23 & 4.38 & 7.82 \\
\hline \multicolumn{6}{|c|}{ PPA CONTENT - $1 \%$} \\
\hline 4.5 & 2.32 & 8.33 & 53.94 & 3.67 & 10.18 \\
\hline 5 & 2.35 & 6.63 & 62.47 & 3.82 & 12.11 \\
\hline 5.5 & 2.37 & 4.11 & 73 & 4.11 & 14.61 \\
\hline 6 & 2.33 & 5.51 & 76.29 & 4.46 & 11.03 \\
\hline \multicolumn{6}{|c|}{ PPA CONTENT - $2 \%$} \\
\hline 4.5 & 2.31 & 7.69 & 65.05 & 3.45 & 10.43 \\
\hline 5 & 2.33 & 5.79 & 67.14 & 4.25 & 13.11 \\
\hline 5.5 & 2.35 & 4.18 & 69.38 & 4.73 & 15.38 \\
\hline 6 & 2.32 & 4.52 & 76.55 & 4.97 & 11.56 \\
\hline \multicolumn{6}{|c|}{ PPA CONTENT - $3 \%$} \\
\hline 4.5 & 2.31 & 8.95 & 52.14 & 3.26 & 18.48 \\
\hline 5 & 2.33 & 7.14 & 60.58 & 3.7 & 20.62 \\
\hline 5.5 & 2.35 & 4.12 & 70.57 & 4.03 & 19.57 \\
\hline 6 & 2.32 & 6.26 & 74.69 & 4.36 & 13.59 \\
\hline \multicolumn{6}{|c|}{ PPA CONTENT - $4 \%$} \\
\hline 4.5 & 2.34 & 7.43 & 57.2 & 3.7 & 13.5 \\
\hline 5 & 2.36 & 6.06 & 64.7 & 4.19 & 15.1 \\
\hline 5.5 & 2.37 & 4.22 & 72.89 & 4.47 & 11.64 \\
\hline 6 & 2.35 & 5.08 & 76.36 & 4.7 & 9.66 \\
\hline \multicolumn{6}{|c|}{ PPA CONTENT - $5 \%$} \\
\hline 4.5 & 2.3 & 9.03 & 51.74 & 3.42 & 10.82 \\
\hline 5 & 2.37 & 5.58 & 66.68 & 4.12 & 14.24 \\
\hline 5.5 & 2.35 & 4.24 & 76.12 & 4.47 & 12.18 \\
\hline 6 & 2.31 & 6.61 & 66.73 & 4.95 & 8.85 \\
\hline \multicolumn{6}{|c|}{ PPA CONTENT - $6 \%$} \\
\hline 4.5 & 2.32 & 8.17 & 54.55 & 3.55 & 11.88 \\
\hline 5 & 2.35 & 6.43 & 63.24 & 4.22 & 13.28 \\
\hline 5.5 & 2.33 & 4.23 & 77.14 & 5.03 & 11.15 \\
\hline 6 & 2.31 & 5.59 & 81.48 & 5.27 & 9.78 \\
\hline
\end{tabular}


From the Marshal Test results, the table simplifies that

a) For conventional mixes stability was obtained at $5.5 \%$ of Bitumen Content.

b) Optimum PPA was obtained at 3\% PPA content for 5\% Bitumen content.

c) As the PPA content was increased stability starts to decrease after 3\% of PPA.

d) Air Voids also starts increasing for optimum PPA and Bitumen Content.

The comparsssion of the tabulated test results were explained through figure $8,9,10 \& 11$ for virgin and different PPA modified bitumen mixes for summarizing the optimum binder and acid content considering better stability, $4 \%$ Air voids with $65 \%-75 \%$ of VFB condiering specific gravity and flow of 3-5 mm. Figures are plotted for bitumen content to various parameters.

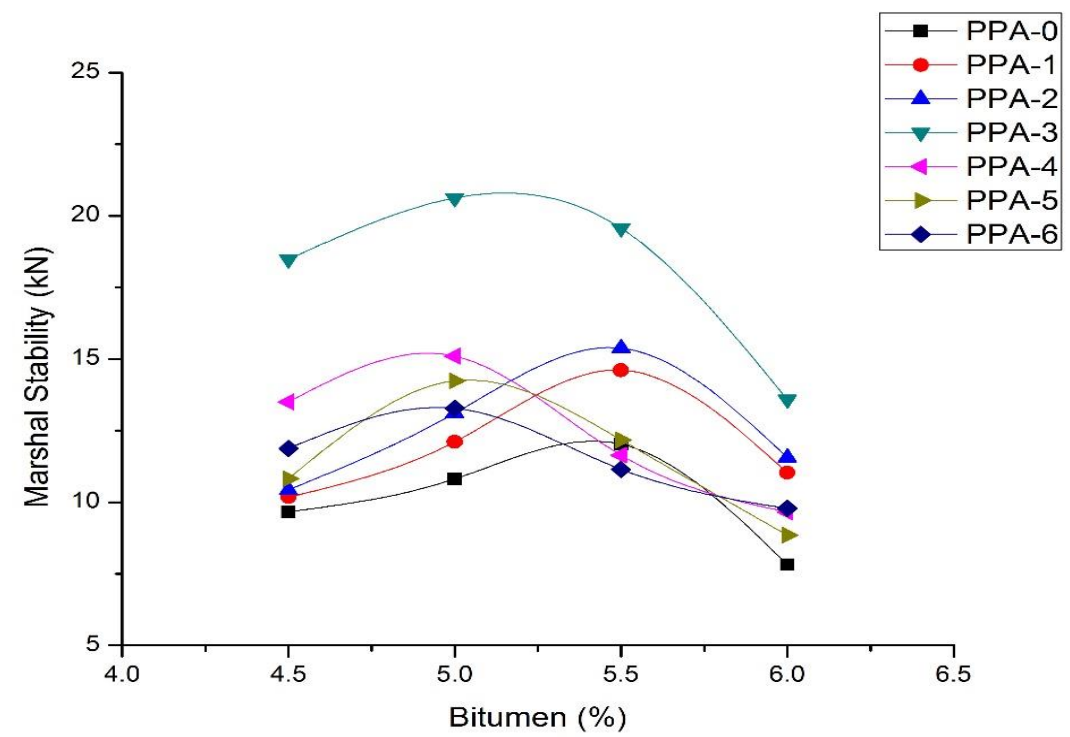

Figure8. Bitumen content Vs Stability

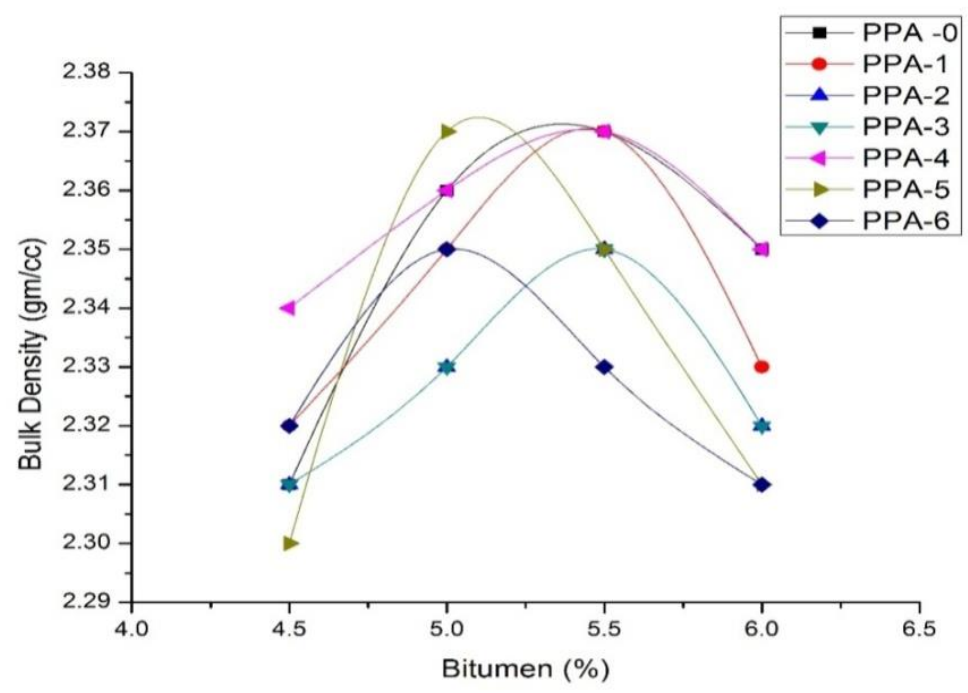

Figure 9. Bitumen Content Vs Bulk Density 
The stability of the each individual mixes are calculated from specifications a high stability was acquired for 3\% PPA but after excess addition of PPA results reduction of stability and increase of bulk density. A similar comparison with conventional mixes are done with individual parameters makes better stability and good density so 3\% PPA is better in stability and density. Now air voids and VFB are plotted to determine the optimum contents as follows.

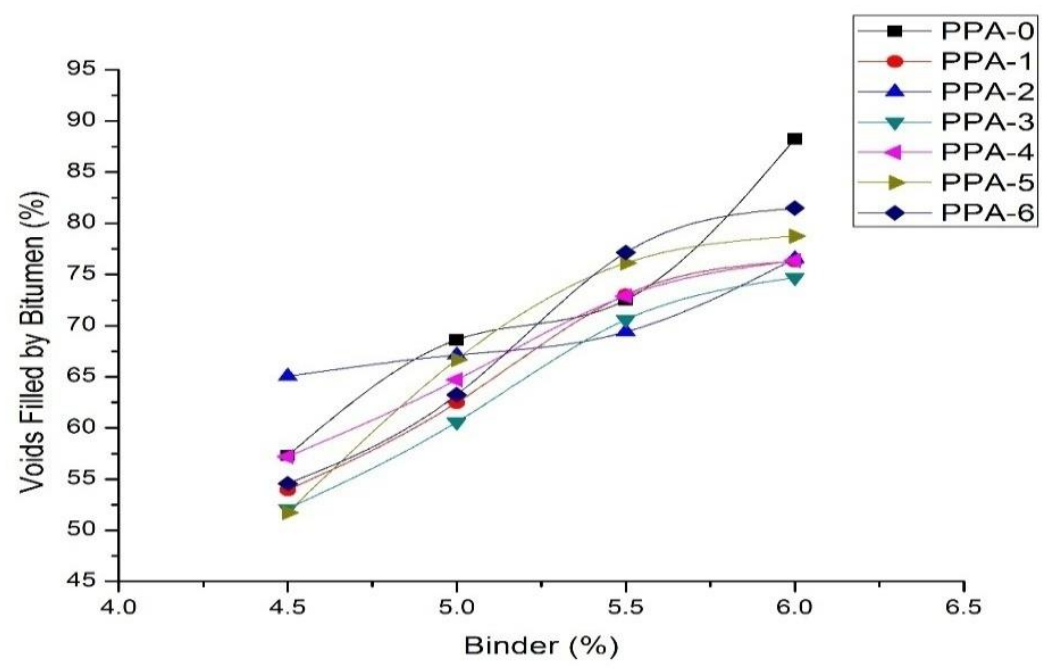

Figure 10. Bitumen Content Vs VFB

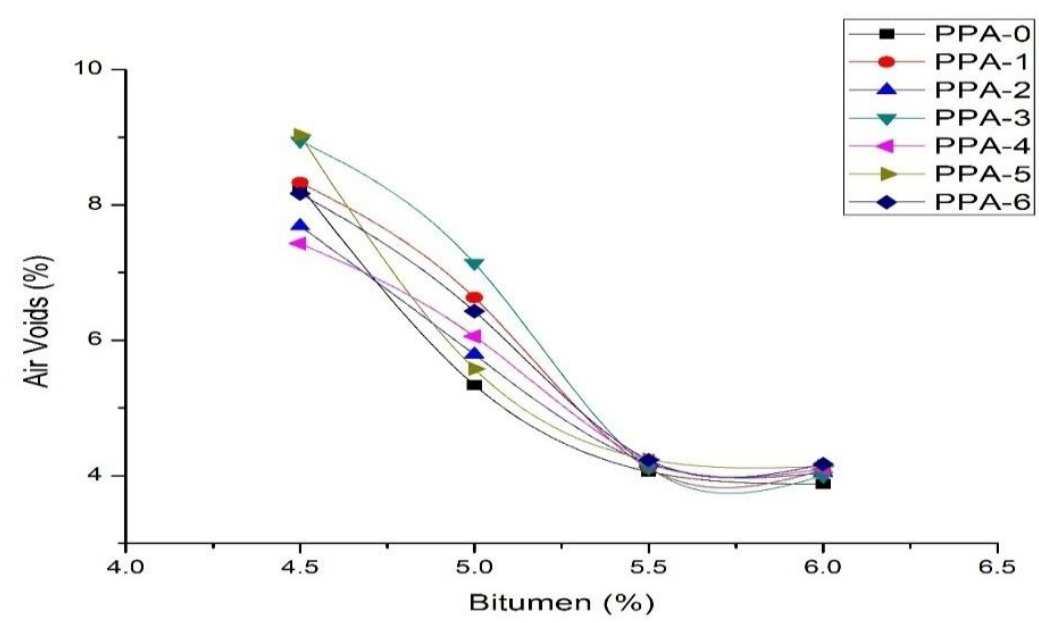

Figure 11. Bitumen Content Vs Air Voids

For the stability curve it is observed that as binder content increases the stability value increase for a maximum $(12.03 \mathrm{kN})$ and air voids reduces from 4.0 to 2.84 for a binder content of $5.5 \%$ to $6 \% .65-75 \%$ of voids filled bitumen was obtained at $5.5 \%$ binder content so $5.5 \%$ binder content for the present study was considered as optimum binder content satisfying MORTH specifications. Conventional mixes is provided with 5.5\% bitumen content as optimum and 3\% PPA mixes gives better stability at 5.0\% bitumen. Which makes the cost of bitumen reduces. Further addition of PPA more than optimum reduces in marshal parameters. This is because PPA does not provided good mixing with virgin mixes at higher content PPA which had resulted in changes in marshal parameters after $3 \%$ optimum. 


\subsection{RUTTING ANALYSIS}

Rutting characteristics is carried through Immersion Wheel Tracking Device, through LVDT the results of rut depth to finite number of passes was acquiesced and monitored through wheel rut test software was obtained in text sheet. The obtained results were analyzed by plotting graph for rut depth to finite number of passes and picturized as follows. Figure 5.21 shows the rut depth of conventional mix for corresponding number of wheel passes for 1,50,000 passes conventional mixes of BC grade - II attain a rut depth of around $18 \mathrm{~mm}$. thus a rut depth for $1 \%, 3 \%, 5 \%$ PPA content bituminous slabs were determined for same $1,50,000$ passes at $35^{\circ} \mathrm{C}$ of temperature as non-immersion test making 35-40 rotations per minute as movement for test performance. The obtained rut depth of those three mixes were plotted as following figure to make a comparison. Figure 12 discusses the rut depth formation of conventional mixes for 1,50,000 passes and Figure 13 shows how the rut depth was formed for $1 \%, 3 \%$ and 5\% of PPA modified mixes for same number of $1,50,000$ passes.

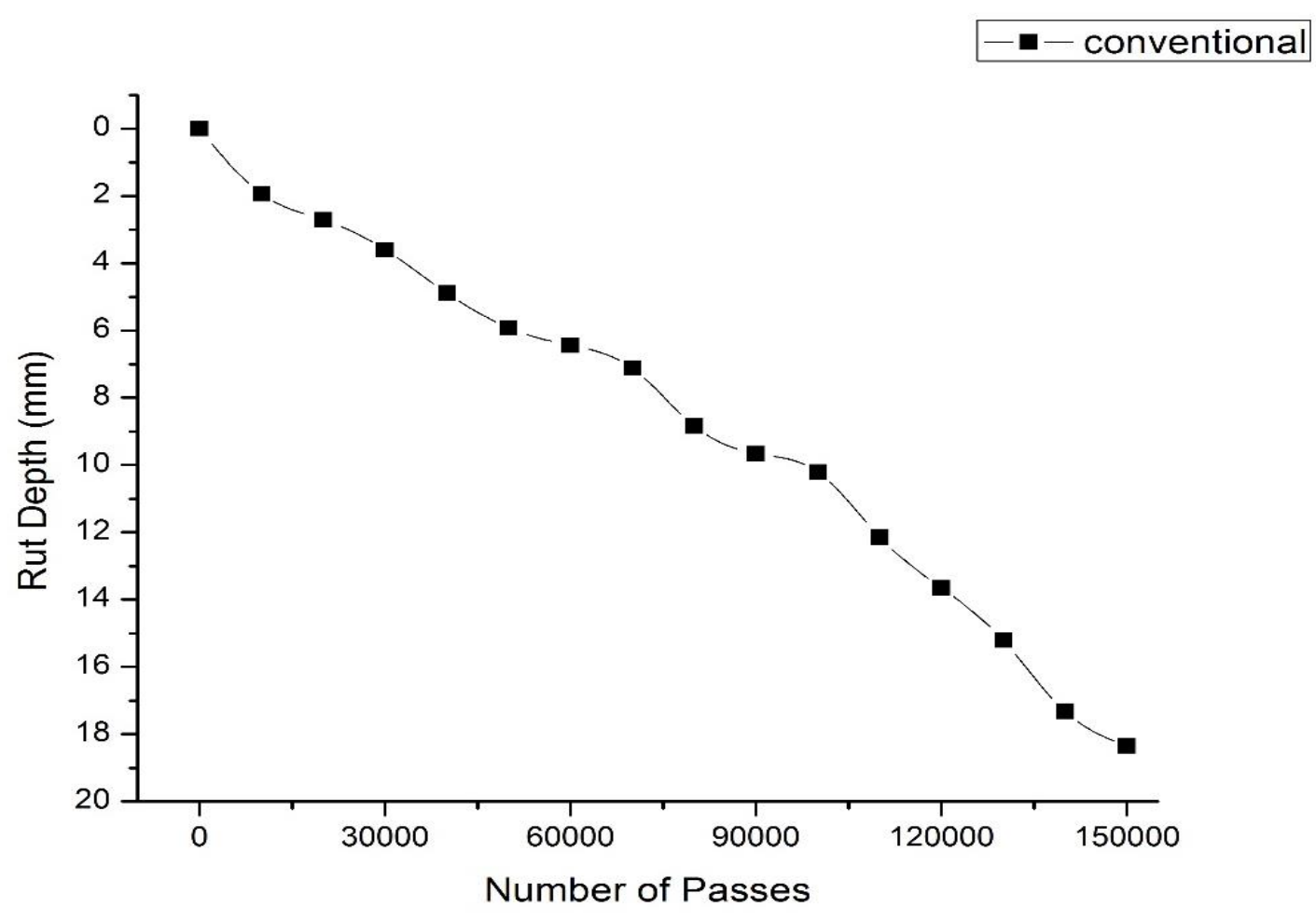

Figure 12. Rut Depth for conventional bituminous mix

The rut depth of conventional mix was fall after 80,000 passes from $10 \mathrm{~mm}$ excess induced number of passes are allowed to find the limited rut depth by IRC:73 that is $20 \mathrm{~mm}$. so making $18 \mathrm{~mm}$ rut depth we obtain at 1,50,000 passes for conventional mixes. Now making $3 \%$ PPA as middle comparative for those number of passes rut depth for three odd percentages are performed to determine the rut depth and through data acquired following comparative graph was drawn. 


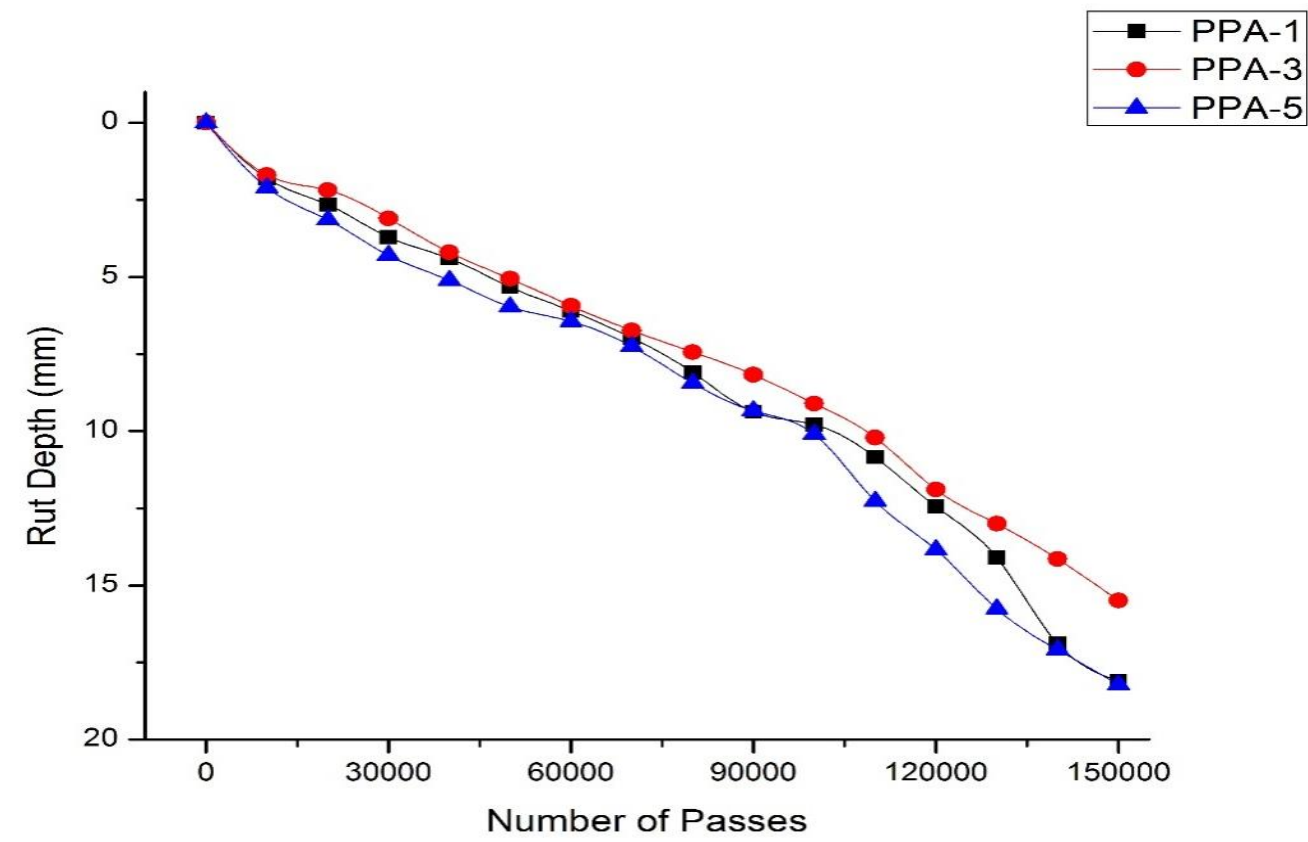

Figure 13 Rut Depth forPPA modified bituminous mixes

The figure $12 \& 13$ explains that for 3\% PPA content rut value is around 3\% lesser than the rut depth for conventional specimen and as PPA content increases rut value increases for induced number of passes and hence 3\% PPA content establishes the stability value and air voids with conventional mixes. Figure $14 \& 15$ shows how rut depth was formed during Rut Test and position of specimen after finite number of passes.
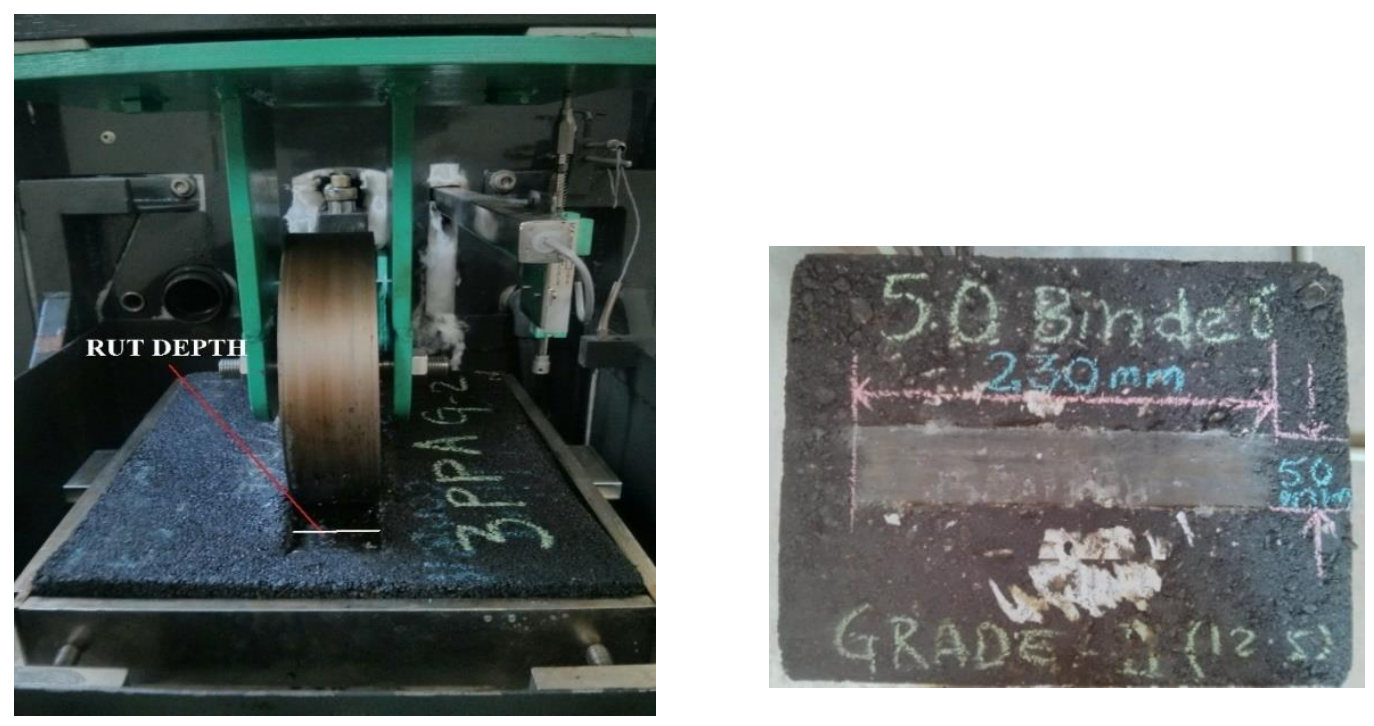

Figure 14. Rut Depth formation during Rut Test Figure 15. Position of Rectangular slab after Rut Test 


\section{SUMMARY\&CONCLUSION}

On the basis of observation and analysis of Marshall Test properties and Immersion Wheel rutting test for Poly Phosphoric Acidmodified mixes the following summarization conclusions are drawn.

- The Marshall Stability value is found maximum of $20.62 \mathrm{Kn}$ for $3 \%$ Poly Phosphoric Acid at $5.0 \%$ bitumen content which is more than conventional bituminous mixes.

- It is observed that air voids decrease, which is necessary for better strength and service life of the pavement and the VFB is also increased by addition of bitumen.

- The bulk density is also found maximum of $2.35 \mathrm{~g} / \mathrm{cc}$ at $3 \%$ added PPA.

- Optimum bitumen content was reduced from 5.5\% to $5.0 \%$ with the addition of $3 \%$ optimum PPA to virgin mix.

- Modification of Bituminous concrete mix has resulted in maximum stability with less bitumen content.

- It is observed that Stability value is increased by $21 \%$ when modified with PPA at $3 \%$ and has air voids of $4.1 \%$ when compared with conventional mix.

- The results of rutting performed on Immersion Wheel rutting apparatus elaborates that there is correlation between stiffness factor and rut depth.

- On comparison with conventional mix and modified mix prepared at 3\% PPA exhibits $4 \%$ less in rut depth at 1,50,000 passes to conventional mixes of VG - 30 .

It is concluded that modification of binder with PPA increases stability, reduces binder content and which also improves rut depth in pavements for same number of passes. This will contribute success in improving serviceability in terms of permanent deformation. IRC 73 has specified to test rutting criteria at standard temperature in future the test can be performed with different temperature conditions considering water bath depends on country's code provisions and specifications.

\section{REFERENCES}

[1] Ahmad. J, Abdul Rahman M.Y and Hainin M.R. (2011) "Rutting Evaluation of Dense Graded Hot Mix Asphalt Mixture” International Journal of Engineering \& Technology IJET-IJENS Vol. 11 No. 05 .

[2] Alaa H. Abed and Adel A. Al-Azzawi (2012) "Evaluation Of Rutting Depth In Flexible Pavements By Using Finite Element Analysis And Local Empirical Model” AJEAS, Vol. 5 No. 02.

[3] Chao Wang and Jinxi Zhang (2014), "Evaluation of Rutting Parameters of Asphalt Binder Based on Rheological Test" IACSIT, Vol. 6 No. 01.

[4] Dr. Ganesh k, Sunil kumarand V. Beli (2013) "Studies on Effect of Wheel Configuration Temperature and Type of Binder on Rutting Characteristics of Bituminous Concrete Mix" IJIET Vol. 2 No.01.

[5] Geraint Lacey, Guillermo Thenoux, Fernando Rodríguez-Roa (2007) "Three-dimensional Finite Element Model for Flexible Pavement Analyses Based On Field Modulus Measurements" AJSE, Vol. 33, No. 1B.

[6] Imran Hafeez, Mumtaz Ahmed Kamal, Muhammad Waseem Mirza (2010) "Evaluation of Rutting in HMA Mixtures Using Uniaxial Repeated Creep \& Wheel Tracker Tests" - PJEAS Vol. 7, July.

[7] Javier Yesid Mahecha, Nunez Matheus David Inocente Domingos and Adalberto Leandro Faxina (2014) "Susceptibility of low-density polyethylene and polyphosphoric acid-modified asphalt binders to rutting and fatigue cracking" - Construction and Building Materials Vol. 73.

[8] Kamran Muzaffar Khan, Mumtaz Ahmed Kamal (2012) "Rutting Based Evaluation of Asphalt Mixes" PJEAS Vol. 11, July. 
[9] Dr. Mohammed SalihAbd-Ali (2013) "A Finite Element Model for Rutting Prediction of Flexible Pavement Considering Temperature Effect” ETJ Vol.31 Part (A), No.21.

[10] Nahi M. H, Ismail A, Ariffin A. K (2011) "Analysis of Asphalt Pavement under Non uniform Tire pavement Contact Stress using Finite Element Method" JAS, vol. 11.

[11] PoornaPrajna S, Dr. Mohamed IlyasAnjum (2014), "Effect of poly phosphoric acid on Marshal properties of Bituminous concrete mixes" IJETAE Vol. 4, No. 7, July.

[12] SaadIssa R. Sarsam, Ali Muhssin S. AL-Shujairy (2014), "Fatigue Potential after Rutting of Sustainable Asphalt Concrete" IJSRK, Vol. 2, No. 12.

[13] Srinivasa Reddy I, Amaranatha Reddy M (2013), "Study on Rutting Characteristics of Bituminous Binders and Mixes" Journal Of The Indian Roads Congress Vol. 73, No. 4.

[14] Vijay B. Kakade, M. Amaranatha Reddy (2014) "Effect Of Type And Quantity Of Binder On Rutting Characteristics Of Bituminous Mix" Indian Highways, March. Codes:

[15] AASTHO T 283, Standard Method of Test for Resistance of Compacted Asphalt Mixtures to Moisture-Induced Damage.

[16] AASTHO T 324, Standard Method of Test for Hamburg Wheel-Track testing of compacted Hot-Mix Asphalt.

[17] ASTM D5581 - 07a(2013), Standard Test Method for Resistance to Plastic Flow of Bituminous Mixtures Using Marshall Apparatus (6 inch-Diameter Specimen)

[18] ASTM D 6926-04, Standard Practice for Preparation of Bituminous Specimens Using Marshall Apparatus.

[19] BS EN 12697-22 (2003), Standard Test methods for hot mix asphalt Bituminous mixtures - Wheel tracking.

[20] IS: 1203-1978, Methods for testing tar and bituminous materials: determination of penetration.

[21] IS: 1205-1978, Methods for testing tar and bituminous materials: determination softening point.

[22] IS: 1206-1978, Methods for testing tar and bituminous materials: determination of viscosity.31. 32.

[23] BS EN 1269733 (2007) Standard Test methods for hot mix asphalt Bituminous mixtures - Specimen prepared by roller compactor.

[24] IS: 2386(Part 1)-1963, Methods of test for Aggregates for concrete: Particle size and shape.

[25] IS: 2386(Part 3)-1963, Methods of test for Aggregates for concrete: specific gravity, density, voids, absorption and bulking.

[26] IS: 2386(Part 4)-1963, Methods of test for Aggregates for concrete: Impact value and Abrasion value.

[27] IRC: SP: 53-2010, "Guidelines on use of Modified Bitumen in Road Construction." 2nd revision, Indian Roads Congress, New Delhi, India.

[28] IRC: 73-2012, “Geometric Design Standards for Rural (Non-Urban) Highways”Indian Roads Congress, New Delhi, India.

[29] Ministry of Road Transport and Highways (MoRTH-2013-5th revision). Thesis:

[30] Imad L. Al-Qadi, Hao Wang (2011) "Prediction of Tire-Pavement Contact Stresses and Analysis of Asphalt Pavement Responses: A Decoupled Approach" A thesis presented to University of Illinois for Doctor of Philosophy.

[31] Olga Shulga, Rene Maldonado and Henry Romagosa (2012), "Effect of Foaming on Performance of Asphalt Binders Modified with Poly phosphoric acid” Thesis Asphalt Paving Technology, Vol. 72.

[32] LudomirUzarowski (2006) "The Development Of Asphalt Mix Creep Parameters And Finite Element Modeling Of Asphalt Rutting" A Thesis Presented To The University Of Waterloo For Doctor Of Philosophy. 


\section{AUTHORS}

1 G. Abdul Khader a PG student (Highway Engineering) of Civil Engineering at VNR VignanaJyothi Institute of Engineering and Technology. His research interest includes Pavement and Traffic safety Engineering, he has worked as Research assistant in Department of Civil Engineering and is involved regular department consultancy projects.

2Dr. A.Ramesh obtained his Doctorate degree from Osmania University. He had published 6 Journal papers and 8 International Conferences papers. He has two research projects funded by AICTE and UGC of worth 16 lakhs. He has 10 years of teaching Research and Consultancy experience. Presently he is working as associate professor in Dept. of Civil Engineering VNR VignanaJyothi Institute of Engineering \& Technology.

3Dr. Kumar Molugaram obtained his Doctorate degree from Indian Institute of Technology, Bombay. He published over 62 research papers in various International and National journals and conferences. He supervised more than 35 M.E. Dissertations and two Ph.D. Thesis. He visited 18 international cities across the world to present his research papers. Prof. Kumar has over 19 years of Teaching, Research and Consultancy experience. Presently he is serving as Professor and Head of Civil Engineering Department and Director Infrastructure, Osmania University.
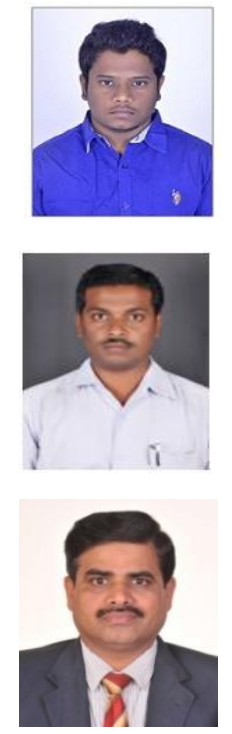